\title{
Biopolítica e Desenvolvimento? Foucault e Agamben sobre Estado, Governo e Violência*
}

\author{
Guilherme F. W. Radomsky
}

Universidade Federal do Rio Grande do Sul (UFRGS). Porto Alegre, RS, Brasil. E-mail: guilherme.radomsky@ufrgs.br

\section{INTRODUÇÃO}

Tá cerca de três décadas, os trabalhos de Foucault despertam inte1 resse para os estudos sobre o fenômeno do desenvolvimento e seus dilemas nos países considerados "Terceiro Mundo". É provável que o artigo de Escobar (1984) tenha sido o primeiro a buscar ler a realidade do desenvolvimento/subdesenvolvimento pela ótica do autor francês, seis anos após a publicação de Edward Said em que, de modo semelhante, a leitura de Foucault inspirou o desvelamento do olhar orientalista como discursos de saber e poder.

Nesse espaço epistêmico, logo se sucederam muitas publicações acerca da temática do desenvolvimento, como Ferguson (1990), Crush (1995), o mais conhecido livro de Escobar (1995), entre outros. Estes escritos situam-se num campo crítico em que o subdesenvolvimento é resultado de construções discursivas, portanto, as políticas de desenvolvimento não são analisadas em suas falhas ou contradições que precisam de ajustes e melhorias; projetos e estudos não apenas examinam e revelam realidades, eles produzem mundos, constituem problemas e diagnósticos a serem tornados legítimos, fomentam a formação de

\footnotetext{
* O autor agradece pelas sugestões e contribuições dos pareceristas que avaliaram o artigo. A pesquisa que deu origem ao texto recebeu apoio financeiro da Fundação de Amparo à Pesquisa do Estado do Rio Grande do Sul (Fapergs) e do Conselho Nacional de Desenvolvimento Científico e Tecnológico (CNPq).
}

DADOS - Revista de Ciências Sociais, Rio de Janeiro, vol. 58, no2, 2015, pp. 537 a 567. 
especialistas, agências e organizações e movimentam recursos que acabam redundando em poucos resultados realmente benéficos (Esteva, 1992; Hobart, 1993; Rist, 2008). Igualmente importantes nesse debate, avaliações críticas não faltaram como respostas aos estudos de inspiração foucaultiana (para mencionar uns poucos, Corbridge, 2007; Storey, 2000; Ziai, 2007).

Dois elementos novos passaram a configurar essa teia de discussões e disputas teórico-epistemológicas. De um lado, a publicação dos cursos de Foucault no Collège de France, material que não estava integralmente disponível aos pesquisadores nos anos 1980 e 1990. Ainda que o seu acesso tenha ocorrido em publicações esparsas em revistas (tais como os que saíram na Aut Aut, na Critical Inquiry e em outras), coletâneas e análises (Rabinow e Dreyfuss, 1982) e em aulas ou palestras de Foucault fora da França, não restam dúvidas de que as compilações com quase integralidade dos cursos têm gerado algumas novidades interpretativas, como por exemplo, sobre os olhares do pensador francês acerca da importância do Estado e do pensamento econômico liberal, a segurança e o planejamento, o social como um campo de intervenções e os processos de subjetivação, ética e verdade. Entende-se que este é um terreno ainda fértil com consequências para a compreensão da "era do desenvolvimento" inaugurada, conforme Esteva (1992) e Rist (2008), no pós-1945. De outro lado, interpretações sobre o par desenvolvimento/subdesenvolvimento se renovam com as recentes publicações de Giorgio Agamben, as quais abalam nossas usuais compreensões sobre o que constitui a política (pelo menos nas sociedades ocidentais) e sob quais prismas podemos entender intervenções da máquina estatal no corpo social, trabalhos que percorrem um caminho analítico amparado em conceitos tais como violência, exceção e soberania.

Sob que condições pretende-se discutir o tema do desenvolvimento neste panorama? Não parecem existir questionamentos sobre a relevância social e política que o assunto continua a alimentar (Kerstenetzky, 2011; Diniz, 2011). Como fato no mínimo curioso, enquanto setores da academia sugerem celebrar o fim da equação entre desenvolvimento e crescimento econômico, a sociedade civil e parte dos atores inseridos diretamente na máquina do Estado revigoram este "casamento", particularmente sensíveis ao espantoso crescimento econômico chinês dos últimos anos e à necessidade de superação da crise econômica na Europa e nos EUA via incremento de empregos e do 
consumo. Especialmente para o Brasil, a retomada desta confiança pode reconfigurar a posição do país no cenário internacional, visto agora como financiador de programas e projetos dentro e fora das suas fronteiras, a ver pelo festejado Programa de Aceleração do Crescimento e pela internacionalização de entidades de financiamento ou pesquisa fora do Brasil.

Com todos os apelos não é de se estranhar que inovações em práticas e políticas acabem recebendo rótulos como neo ou "novo-desenvolvimentismo", que pululam em periódicos e livros recentes, às vezes discutíveis se são novidades ou anacronismo, como sustentou Werneck Vianna (2012). Estabelecer uma continuidade entre o sonho desenvolvimentista das décadas que sucederam o pós-guerra com seus planos grandiosos de crescimento econômico e os novos arranjos do desenvolvimento parece tarefa menos factível. Mais ainda: não soa estranho aceitar uma convergência entre violência e desenvolvimento, quando tudo aquilo que deveria estar sob a "guarda" do último termo é a criação de melhores condições de vida, expansão de liberdades, garantia de direitos econômicos e acesso a políticas públicas?

Este artigo se coloca o desafio de mostrar estas relações de afinidade sem que para tal seja preciso abdicar de todos os ganhos sociais que apenas alguns testemunharam ao longo dos anos; mais que isto, não significa rejeitar o desenvolvimento a priori nem supor que, por motivos ecológicos (que já seriam razoáveis), deveríamos aceitar a desigualdade de distribuição de "recursos" entre países do Sul e do Norte. Então, se é assim, para que prosseguir nesta linha de investigação já que as pesquisas marxistas, dependentistas e estruturalistas mostraram as contradições inerentes a esses processos?

Algumas pistas indicam um problema adicional que, poder-se-ia dizer, está associado a uma vontade irrefreável de desenvolvimento, a meio caminho da mística e do desejo inacessível, e isto tem aparecido em monografias, tais como Taussig (1992) e De Vries (2007). Estas surgem num cenário posterior às publicações de cunho pós-estruturalista (Escobar, 1995; Ferguson, 1990) ou em torno do programa de decrescimento (Latouche, 2009), as quais procuraram mostrar os efeitos deletérios do desenvolvimento e sua racionalidade instrumental. No entanto, o que chama a atenção é que o desejo aparece em alguns casos simultaneamente (e surpreendentemente) conjugado à repulsa ou ao medo, geralmente em relação à figura estatal como ente que "leva" 
programas e projetos aos recônditos proliferando vontades crescentes ou gerando ambiguidades.

Assim foi que, em uma recente pesquisa de campo, tive que lidar com esta situação. Depois de já estar realizando a investigação durante alguns meses entre pequenos agricultores no oeste de Santa Catarina, e com um conjunto de dados bastante razoáveis para a análise, percebi haver uma negligência do trabalho que precisava ser corrigida: o Estado e sua participação nos processos de desenvolvimento. $\mathrm{O}$ foco da pesquisa concentrava-se na agricultura ecológica e, por razões que explico a seguir, era muito pouco estimulante buscar entender as relações dos agricultores com o Estado durante o período inicial da pesquisa. Ao verificar esta lacuna compreendi o motivo: em muitos momentos até então convividos com os interlocutores em campo, a imagem/representação acerca do Estado por parte deles era cambiante e ambivalente. Este processo parecia deixar poucos subsídios para empreender um exame mais minucioso e desviava a atenção para outros aspectos.

Em determinados momentos, isto assumiu a condição de impeditivo, fazendo com que a incapacidade de um diagnóstico preciso se transformasse em negação da questão. A ambivalência e a instabilidade dos discursos pareciam mistificar a situação. De que se trata tal ambivalência? Em diferentes ocasiões, agricultores ecológicos demonstravam expressiva atração pelo Estado; em outras, e alternando sem problemas, sublinhavam repulsa com maior ou menor intensidade. Entre uma e outra, situações em que a dificuldade de entender seus posicionamentos gerava mais problemas.

Os dilemas dos processos e das políticas de desenvolvimento frente a essas situações são, portanto, o objeto deste artigo. Além desta relação entre desejo e repulsa, medo e atração, buscar-se-á precisar sob que condições torna-se possível estabelecer conexões entre desenvolvimento e violência. Os dados apresentados junto às reflexões são oriundos de pesquisa de campo realizada, em sua maior parte, entre 2007 e 2009 no oeste do estado de Santa Catarina entre distintos atores sociais envolvidos em programas e projetos de desenvolvimento, especialmente para a promoção da agricultura ecológica. Do ponto de vista teórico, a intenção é realizar uma incursão num terreno ainda pouco explorado. Propõe-se uma interpretação sobre o nexo violência/desenvolvimento na interseção entre desejo/repulsa e, com esta finalidade, acessar um locus compreensivo singular no vértice formado por Michel 
Foucault e Giorgio Agamben do triângulo que inclui ainda Walter Benjamin.

Conhecido pela publicação da série Homo Sacer, Agamben tem polemizado os estudos sobre biopolítica ao radicalizar os argumentos em favor de uma história mais longa da noção de política sobre a vida (2002). A proposição corrói o argumento (forte) do pensamento europeu ocidental que se imagina herdeiro direto do exercício da deliberação e da democracia da Grécia antiga. Para o autor italiano, e este artigo procurará mostrar sucintamente os caminhos metodológicos de suas conclusões, a política ocidental vive a antiga - porém crescente - inscrição da vida (nua) na ordem jurídico-política. Para tanto, será preciso passar por Foucault e, após, examinar as conexões entre soberania e o modelo gerencial-econômico de condução da sociedade e a administração da vida. Interessa sugerir que esta possibilidade recoloca perguntas em torno de programas de ação/intervenção sobre a sociedade para indagar se desenvolvimento é expansão do bem-estar ou, inversamente, um conjunto heterogêneo de intervenções de impulso modernizante geralmente de locus estatal, porém não exclusivamente - sobre a vida das pessoas e, por efeito, segue-se um ordenamento de poder/violência juridicamente aceito (mesmo que a intenção seja inclusiva).

O artigo está dividido em cinco seções após esta Introdução. Inicia-se abordando o pensamento de Foucault e os problemas em torno de segurança, normalização, biopoder e governo. A parte seguinte examina os escritos de Agamben sobre Estado, violência, biopolítica e banimento. Passa-se, então, ao estudo de processos sociais em que a derivação da arquitetura conceitual entre Foucault-Agamben forma um plano de análise. Ao final, considerações são tecidas.

\section{COLONIZAÇÃO OU NORMALIZAÇÃO: DA DISCIPLINA AO "GOVERNO COMO NÃO GOVERNO"}

Para entender a disputa sobre o que consiste o projeto de "desenvolver os subdesenvolvidos", pode-se partir do conflito de interpretações que rondam a obra de Foucault. Um dos motes polêmicos é a possível equação entre colonização e desenvolvimento, trabalhada especialmente por Escobar (1995) quando afirma que a realidade dos países do hemisfério Sul no pós-Segunda Guerra tem sido colonizada por meio do desenvolvimento. No que consiste tal problema para os críticos deste argumento? A própria obra de Foucault é lida como meio para desti- 
tuir esta afirmação, pois o problema reside em diferenciar minuciosamente normalização de colonização. Nesta linha, teriam os críticos radicais do desenvolvimento abusado da metáfora da colonização dos povos do "Terceiro Mundo" pelo desenvolvimento? Brigg (2002) entende que equacionar colonização e desenvolvimento é recusar ver que o desenvolvimento constitui sua força por seu modo sutil de "poder positivo" e preocupado com um tipo de administração que visa superar o subdesenvolvimento e a pobreza (Brigg, 2002; Foucault, 2008a). Normalização não opera pela supressão dos sujeitos, ao contrário, é pela inclusão administrada que os integra aos regimes de poder (Brigg, 2002:428). Retornarei a isto.

As interpretações de Escobar sobre o assunto são conhecidas e não serão esmiuçadas; elas remetem a uma perspectiva em que o desenvolvimento infantilizou os povos do Terceiro Mundo, organizou um dispositivo orientado à promoção da mudança social por meio de intervenções organizadas por entidades e profissionais e criou efeitos instrumentais ao permitir que o desenvolvimento se tornasse uma espécie de teoria da salvação secular (Escobar, 1995; Ribeiro, 2008).

Recuperemos por instantes algumas passagens dos cursos publicados de Foucault ${ }^{1}$. Observando-se com acuidade, existem importantes rupturas históricas e que constituem desafios a pensar a continuidade linear entre normalização e colonização. É possível que o ponto-chave seja o funcionamento e o mecanismo do poder. Três diferentes manifestações do poder são recuperadas por Foucault: o poder soberano, o disciplinar e o biopoder. O soberano é amplamente fundamentado no poder absoluto e no uso do terror. Então, o autor adverte que a partir dos séculos XVII e XVIII surge uma nova mecânica de poder diferente daquela colocada em ação pelo soberano. É um poder disciplinar que age sobre corpos, utiliza-se de técnicas de vigilância e procura extrair dos corpos humanos o tempo e o trabalho. Conforme Foucault, esse poder disciplinar está encaixado numa trama de coerções materiais e torna-se um vetor de propulsão do capitalismo na maneira como essa rede de relações orientou a disciplina para o trabalho (e para a formação do trabalhador sadio). As técnicas guiam-se por coerções sobre o corpo individual em que se impõe um conjunto de disciplinas: distribuição espacial, separação, alinhamento, serialização e vigilância, tanto no ambiente de trabalho como na escola (Foucault, 1999:288 e ss.). Organizar e visibilizar criavam condições para a manutenção das hierarquias e para a consecução de inspeção e relatórios. 
Nos séculos XVIII e XIX outra tecnologia começa a se apresentar, não exatamente disciplinar. Mas Foucault ressalta: esta não substitui a anterior, ela a integra, modificando-a parcialmente e, particularmente, aproveita-se da disciplina prévia. Esta nova tecnologia se dirige não mais ao corpo, mas ao ser humano vivo, homem-espécie. No homem-espécie, aparece o problema da massa populacional a ser governada e normalizada. Estamos em face do biopoder. Portanto, nessa relação do ser humano e sua natureza vemos a biopolítica propriamente dita, e segue o autor afirmando numa conhecida passagem que "depois da anátomo-política do corpo humano, instaurada no decorrer do século XVIII, vemos aparecer, no fim do mesmo século, algo que [...] eu chamaria de uma biopolítica da espécie humana" (1999:289). Seus procedimentos se amparam tanto em aspectos demográficos (controle de natalidade, envelhecimento) como médicos (saúde pública, anomalias e higiene) com a conexão a elementos econômico-sociais, tais como seguridade, assistência, segurança, planejamento agrícola, cuidado do bem-estar, policiamento das ruas e condições para circulação de mercadorias. Retornarei a estas características mais adiante; neste momento, vale destacar como a noção de biopoder aparece no curso de 1975 /1976 (também no volume A Vontade de Saber da História da Sexualidade) e é retomada em 1977 / 1978 na primeira exposição do curso. Biopoder é

o conjunto de mecanismos pelos quais aquilo que, na espécie humana, constitui suas características biológicas fundamentais vai poder entrar numa política, numa estratégia política, numa estratégia geral de poder. Em outras palavras, como [...] as sociedades ocidentais modernas, a partir do século XVIII, voltaram a levar em conta o fato biológico fundamental que o ser humano constitui na espécie humana. (Foucault, 2008a:3)

Seria o biopoder sinal de menos poder? Não, apenas um tipo diferente. A distinção traçada entre o poder soberano e o biopoder sugere que, se o soberano atuava pelo código "fazer morrer, deixar viver" como modo de controle sobre vida e morte, o biopoder inverte os termos para "fazer viver, deixar morrer" (ver Agamben, 2002). Normalizar é também incluir - por meio de um poder positivo que procura preservar a vida ao custo de uma população governamentalizada. E será no curso dos anos 1977/1978, redirecionando a reflexão para governo e população, aquele em que Foucault define governamentalidade como 
o conjunto constituído pelas instituições, os procedimentos, análises e reflexões, os cálculos e as táticas que permitem exercer essa forma bem específica, embora muito complexa, de poder que tem por alvo principal a população, por principal forma de saber a economia política e por instrumento técnico essencial os dispositivos de segurança (Foucault, 2008a:143).

Essa prática de governo teria nascido da articulação entre a pastoral cristã, a técnica diplomático-militar e uma noção de polícia da época. No curso do ano seguinte, O Nascimento da Biopolítica, o autor reconceitua governamentalidade tornando a definição mais sucinta (e mais ampla) ao afirmar que ela significa basicamente o "modo de conduzir as condutas" das pessoas, alicerçando-a em uma análise do poder em geral, embora colocando o Estado neste cruzamento ao deslocar a discussão de poder para governo e suas técnicas (Foucault, 2008a, 2008b; Senellart, 2008).

Uma peça faltante até aqui é a que diz respeito ao espaço de intervenção que possibilitou o exercício de uma biopolítica. Tal qual havia declarado que o ser humano não existia até poucos séculos do modo como o conhecemos hoje (Foucault, 2002), agora mostra algo paralelo à sociedade e à economia. Em algum momento, já no que chamamos de modernidade, não é mais o espaço (no sentido de controle territorial) o vital para a dominação soberana, mas a população e as coisas. O poder não será medido pelo tamanho do território de um país, e sim pela força de trabalho e pela capacidade de produzir objetos valiosos. Assim surge a ideia de uma economia possível de ser pensada ou planejada dentro das fronteiras do Estado, retomando a velha noção de economia, mas enfatizando a administração de coisas (bens) e pessoas, que devem ser disciplinadas pelos saberes médicos, escolares e pelo trabalho.

Se nesse eixo de coordenadas encontramos a economia, é num plano similar que o social emerge também como campo de problemas e relações, especialmente nas obras de pensadores clássicos que ajudaram a modelar nosso mundo.

A sociedade como uma naturalidade específica à existência em comum dos homens, é isso que os economistas, no fundo, estão fazendo emergir como domínio, como campo de objetos, como domínio possível de análise, como domínio de saber e de intervenção. A sociedade como campo específico de naturalidade própria do homem [...]. (Foucault, 2008a:470) 
Não parecem existir dúvidas de que Foucault tem como projeto mostrar que essa suposta "naturalidade" não tem nada de natural e a noção de polícia do século XVII demonstra um elo fundamental. Os Estados europeus ocidentais testemunhavam o crescimento de sua força e o sentido de uma sociedade regulada por premissas de boa ordem se torna mais comum, em um termo, no escopo da polícia. Porém, Foucault sustenta que essa noção de polícia é diferente da que hoje entendemos, ela é mais vasta e possuía uma conotação positiva. Era tarefa da polícia criar atividades para a população e zelar pelo bem-estar geral, conduzindo os Estados e as sociedades a chegarem num patamar de perfeição. O autor mostra um conjunto amplo de características e tarefas a cargo dessa instituição que incluía policiamento, entretanto articulavam todo o tipo de regulação e disciplinamento de condutas. Num momento em que parece coincidir com a emergência do biopoder, esse antigo projeto de polícia se decompõe em quatro elementos: prática econômica, gestão da população, direito e respeito às liberdades e polícia (no sentido aproximado ao atual) (Foucault, 2008a, 2008b). Parece estar a um passo a articulação entre polícia e policy.

O que parece estar no horizonte do autor é uma articulação entre as noções de poder, segurança e risco, haja vista o tipo de configuração social que emergia na Europa depois do século XVII e que estará orientada para o policiamento e a administração da sociedade por mecanismos de poder descentralizados e, eventualmente, dispersos. Ainda assim, é importante observar que Foucault percorre muitas aulas falando do poder do Estado, inclusive mostrando em diferentes contextos nacionais a organização de uma Ciência do Estado².

No regime anterior a disciplina regulamenta tudo, nada a escapa. Já o modelo da segurança, o preceito se transmuta em deixar fazer. Começa a emergir um pensamento que irá sustentar que a realidade tem um desenvolvimento próprio, projeto típico do liberalismo, em que as coisas precisam "andar" sem disciplinamento excessivo. Essa condição efetua uma mudança singela, porém importante, para a qual não se trata mais de fazer coisas, pessoas e relações funcionarem por meio de obrigações disciplinares. Já não estaria em curso uma mera relação de obediência à vontade superior (do soberano ou à disciplina), mas fazer os "elementos da realidade funcionarem uns em relação aos outros". Segue dizendo que os processos devem ser físicos, ou seja, "naturais, elementos da realidade" (Foucault, 2008a:86). 
Acerca do "funcionamento natural do social", o andamento da exposição indica que será somente no último curso examinado aqui que Foucault mostrará as relações entre governar e laissez-faire. Neste momento, o autor está interessado em traçar genealogias do pensamento econômico-liberal e, particularmente, em articular premissas liberais e neoliberais, caras ao nosso tempo. Neste terreno surge uma importante luz sobre "não governo" como forma de governo. No que consiste? Na mudança em direção à limitação da arte de governar que alicerça uma espécie de razão governamental moderna (Foucault, 2008b:14). Para os liberais, o problema do poder não é o abuso da soberania, mas o excesso de governo. Não há espaço para demonstrar o uso abrangente do autor de dados históricos e obras do período de formação do liberalismo e suas transformações, mas cabem algumas importantes observações sobre mercado. Essa categoria basilar aos poucos adquirirá centralidade como palco da ação humana. Operando modificações no regime de saber-poder, o mercado aparecerá, na ótica dos economistas liberais, como um espaço de formação da verdade (ibidem:44). A enunciação de verdade corresponderia ao intrínseco da interação humana, portanto, o mercado como palco naturalizado da ação colocar-se-á como limitação ao governo toda vez que este ensaiar intervenções indesejadas na ordem das coisas e dos interesses. $\mathrm{O}$ bom governo torna-se aquele que pouco governa e somente será compreendido por nós sob a condição de que esta arte é intencional e não diz respeito a alguma natureza humana de fato, apesar dos anseios dos liberais, afirma Foucault. Governar, para estes, é deixar os interesses se manifestarem; e o mercado, através das trocas, determinar o valor das coisas.

É sob este prisma que o liberalismo será definido por Foucault com base em três condições: "Veridição do mercado, limitação pelo cálculo da utilidade governamental e, agora, posição da Europa como região de desenvolvimento econômico ilimitado em relação a um mercado mundial" (ibidem:83).

Justamente no âmbito de uma (bio)política inclusiva e que quer preservar a vida que a máquina do desenvolvimento pode agir enquanto dispositivo de atração e os argumentos liberais têm uma sutil participação nisto. Se a perspectiva do poder soberano colonial se ampara, como mostram Mignolo (1995) e Quijano (2000), em torno da diferença colonial irredutível, o desenvolvimento é como um aparato de ligação em que se pode vislumbrar a superação das condições (subdesenvolvidas), assim uma forma de narrativa e prática que permitirá o sonho do 
desenvolvimento se tornar acessível aos povos do mundo. Provavelmente, e este mecanismo é sintomático, o sonho estará para todos, e não sua realização. Como bem mostrou De Vries (2007), a máquina do desenvolvimento coloca em movimento pulsões de desejo e ela só pode se tornar factível de sonho tendo em vista a "possível" e almejada realização. Sob este ponto de vista, o debate sobre colonização e normalização volta a se apresentar. Brigg argumenta que "o desenvolvimento opera através da mobilização dos interesses e aspirações dos sujeitos e nações do Terceiro Mundo, em contraste com a modalidade [...] do poder colonial" (2002:424) ${ }^{3}$. Embora o biopoder seja uma forma diferente, ele não parece representar a dissolução dos mecanismos de sujeição. Operar pela aspiração e pelo desejo pode ser conveniente, normaliza-se ao distribuir e incluir, porém atualiza uma colonização não mais pelo terror, e sim pelo fechamento a possibilidades que estejam além do desenvolvimento.

Curiosamente, no âmbito mesmo das políticas intervencionistas do desenvolvimento, encontramos elementos que se assemelham a condutas liberais. Foucault (2008a:391) nos adverte que, quando Estados ou príncipes não buscarem mais se espelhar em impérios, tal como nos registros do passado (império macedônio ou romano e mesmo no império espanhol, mais recente), é a concorrência econômica que valerá como luta (no sentido de disputa no plano internacional) e como regulador de conflito, já que surgem os pactos pela paz e a noção de balança de poder. Não é sem razão que as trocas econômicas e os tratados científicos procurarão demonstrar os ganhos nas teorias das vantagens comparativas. No curso de 1978 /1979, a distinção entre pensamento liberal e neoliberal apresenta uma importante assertiva para tal problema: se entre os liberais o mercado se apresenta como espaço de troca, entre os neoliberais ele se coloca como lugar de concorrência, então a ideia geral de equivalência é substituída pela de desigualdade (eventual resultado da competição, embora com igualdade formal). Mais que críticas ao eventual excesso de governo, no neoliberalismo o mercado é que se torna modelo de conduta, inclusive para gestão do Estado, mesmo que o último ponto de distinção pareça contradizer: não se trata de um mercado autorregulado puramente, o neoliberalismo do século XX aposta no constante monitoramento da economia e na intervenção no social de modo a preservar a dinâmica de mercado (Foucault, 2008b). 


\section{ESTADO DE EXCEÇÃO, BANIMENTO E BIOPODER: A VIDA NUA ADMINISTRADA}

Comecemos por um cenário conceitual em Agamben razoavelmente distinto do traçado por Foucault na expectativa de encontrarmos ligações aos poucos. A seguinte situação paradigmática é ilustrativa. Relacionando exceção, Estado e poder de intervenção na economia, Agamben (2004:37) recupera um discurso de Roosevelt na época de grande crise econômica americana: "Pedirei ao Congresso um único instrumento que me resta para enfrentar a crise: amplos poderes executivos [...], poderes tão amplos quanto os que me seriam atribuídos se fôssemos invadidos por um inimigo externo". Argumento elaborado em poucas linhas, para Agamben há um paralelismo no século XX entre a emergência militar e a econômica.

Embora Agamben não afirme francamente, este tipo de intervenção econômica seria paradigmática do modelo de condução política contemporânea. Aos poucos, espero tornar claro ao leitor qual a pertinência disto para a temática do desenvolvimento, contudo alguns caminhos intermediários necessitam explanação. O ponto central está em afirmar que o estado de exceção, tema ao qual consagra um livro, se desloca no mundo moderno de um artifício excepcional para casos urgentes em direção a uma "técnica de governo" (Agamben, 2004:13). O autor discorre dezenas de páginas traçando suas genealogias, as instituições da qual deriva na Roma antiga, passando por diferentes termos empregados e teorizados (estado de sítio e outros).

Paralelamente, um dos motes analíticos é orientar-se no debate travado entre Walter Benjamin e Carl Schmitt sobre soberania e exceção nos anos 1920-1930. Aparece em seus esforços mostrar que o estado de exceção não é uma zona fora do estado de direito, mas, no limiar dela e da qual ela se nutre, uma espécie de zona de anomia. No entanto, ele parece essencial à ordem jurídica, no sentido estratégico, tal como Roosevelt acima apelava para poderes extraordinários. Agamben afirma que "é a essa indecidibilidade e a esse não lugar que responde a ideia de uma força de lei" e segue: "É como se a suspensão da lei liberasse uma força ou um elemento místico, uma espécie de mana jurídico [...] de que tanto o poder quanto seus adversários, tanto o poder constituído quanto o poder constituinte tentam apropriar-se" (2004:79).

Grifei a palavra limiar anteriormente para demarcar um termo caro ao autor. Qual a relação entre exceção, soberania e Estado? Esta parece ser 
uma articulação que reverbera no assunto desenvolvimento, sobretudo quando se trata de examinar o papel do Estado. Tudo indica que a política não emerge como locus de deliberação e democracia na história ocidental, nem sequer é (na realidade) seu modelo. Antes, a política para Agamben está vinculada ao controle sobre a vida e ao limiar da ordem jurídico-política que a soberania desenha (2002). Num dos livros que inaugura este problema, o autor sugere que sua problemática consiste em traçar um cruzamento entre o modelo jurídico-institucional da política com o modelo biopolítico, já que a implicação da vida nua (a mera vida) viria a constituir o núcleo de origem do poder soberano. Desta maneira, tal como Foucault apresenta - embora para este o fenômeno seria relativamente recente -, o poder sobre a vida, tomando-a eventualmente como uma vida sem qualificação como pura vida biológica, é o atrator sobre o qual o poder será exercido. Sob este prisma Povinelli (2012) afirma que para Agamben o poder, sempre exercido sobre o corpo, está no limiar de tratar o humano como vida nua e vida qualificada - este é o exercício soberano de poder, uma decisão que a afeta com a possibilidade de morte (também em Sylvester, 2006; Fleury, 2013) $)^{4}$.

Ruiz nos apresenta mais argumentos para estabelecer elos entre o tema da exceção e o poder soberano sobre a vida como problema fundamental da política. Nos estados democráticos modernos, afirma Ruiz, o soberano é também aquele que pode decretar quais populações são perigosas para sociedade como um todo e afirma que "a vida humana é capturada dentro da ordem através da figura da exceção. Isso significa que [...] a vida humana existe dentro do direito, mas sempre com a potencial ameaça de ser excluída do direito" (2012:05).

Este panorama contradiz e se afasta dos argumentos de Foucault sobre biopoder e sua armadura de dominação que preserva a vida? Aparentemente sim, porém no núcleo dos detalhes há ressonâncias. Um ponto de expressivo contato encontra-se na importância da lei para a ordem e no campo da soberania. Foucault (1999) mostra que para a soberania o problema do direito no mundo ocidental está em resolver a questão da dominação, no sentido de dissolver ou mascarar uma enunciação violenta para os direitos legítimos tendo como contrapartida a obediência como obrigação legal. Mais adiante, o autor sustenta que "a lei não é pacificação, pois, sob a lei, a guerra continua a fazer estragos no interior de todos os mecanismos de poder, mesmo os mais regulares" (1999:59). Ao compararmos esta leitura aos escritos de Agamben, per- 
cebemos o ponto de união possível no famoso ensaio de Benjamin (1986), primeiramente traduzido no Brasil com o título duplicado de "Crítica da Violência. Crítica do Poder" (e que uma versão mais recente da tradução opta somente pelo termo violência), embora Foucault não faça referências a ele. Agamben sinaliza que nossos esquemas jurídicos justificam a lei como superação da violência, mas de maneira oculta ela mesma se encontra justificada nos dispositivos legais. Claramente inspirado no ensaio de Benjamin, a lei aparece como criação mítica e preservação dos códigos jurídicos (Agamben, 2004). Para Foucault (1999:197), diferente do que o direito e a filosofia buscaram ensinar, a verdade e o logos não iniciam no momento em que a violência cessa. Por isso, a recuperação do ensaio benjaminiano cujo objetivo é garantir a possibilidade de uma violência fora do direito, que romperia com o círculo ao destruir a interdependência entre a violência que funda e a que conserva o direito.

Parece-me que Agamben invoca as categorias de estado de exceção e da violência não para pensar uma continuidade linear e sem rupturas entre o poder soberano-territorial e as táticas modernas de governo dos vivos. Na realidade, entre os livros Estado de Exceção e O Reino e a Glória uma mudança de ênfase é percebida, pendendo no segundo para os atributos do ato de governar, da aclamação política e da teologia econômica. Em que consiste tal deslocamento? A partir de um momento no Ocidente houve uma inflexão, de origem cristã e bastante antiga, para um modo de conceber a política calcado nas noções de economia, gestão e governo. Esta se orienta para administrar as coisas do mundo e os humanos e tem como modelo a oikonomia, a "gestão/administração da casa" que no mundo grego antigo era um modelo de gestão doméstico ${ }^{5}$. Este modelo na vida grega era privado e não democrático, diferente da vida pública. Neste caso, Foucault (2008a:127) está muito próximo do argumento ao afirmar que governar é trazer o modelo da economia (administração doméstica) para o mundo político. Nos cursos de Foucault, no fim dos anos 1970, há clara propensão a refletir sobre a noção de governo com base no modelo da gestão da população.

Agamben (2011) relembra, ao comentar os escritos de Foucault, que um atributo crucial da governamentalidade é sua vinculação à pastoral cristã e a expressão omnes et singulatim em que a economia das almas se atualiza na forma de governo gerencial de todos e de cada um. Governar "todos e cada um", função do pastor, parece operar bem o que 
Foucault procurava associar entre a disciplina do corpo individual e o governo das massas, para os quais a máquina governamental em movimento, execução e administração se torna capital.

Toda esta inflexão para a noção de governo inspirada na categoria oikonomia aponta novamente para o sentimento de que no mundo moderno ocorreria menos poder, entendido como menos violência. Ocorre que gerenciar não pode acontecer sem que dispositivos estejam operando, no sentido de dispor e organizar (problemática central para programas e projetos de desenvolvimento).

Sob este prisma, vejamos o que mais Foucault assinala sobre o polêmico problema da normalização. Entre lei e violência, o argumento torna-se mais nuançado e, retornando à biopolítica, nos deparamos com as passagens em que o autor recorre à convivência histórica entre disciplina e biopoder. Aqui a tensão aparece entre a lei e a norma; Foucault utiliza exemplos das cidades operárias em que a disciplina sobre os corpos individuais se combina com controles médico-biológicos da população e da sexualidade e a norma opera como articulador. A um só tempo, a norma age sobre o corpo individual e regulamenta a população, e "a sociedade de normalização é a sociedade em que se cruzam [...] a norma da disciplina e a norma da regulamentação" (Foucault, 1999:302). Portanto, caberia indagar se a normalização estaria de fato tão distante dos atributos de colonização e violência e, paralelamente, refletir quais atributos deste modelo de poder/governo são atualizados em todas as iniciativas que desejam desenvolver uma população por meio de ações administradas e controladas. Uma interpretação de Sordi para o problema teológico da governamentalidade em Agamben pode ser esclarecedora: "Se a governamentalidade é uma 'arte de administrar pessoas e coisas', poderíamos argumentar que sua assinatura teológica também a faz ser uma arte de administrar pessoas e coisas de acordo com um projeto, de acordo com um fim" (2013:150).

Estaria a noção de governo gerencial mais para o âmbito da intervenção, da regulação administrativa da vida social (e o desenvolvimento como melhorar as coisas, fazer as relações entre pessoas e coisas funcionarem) e, portanto, teria alguma relação com o problema não democrático do estado de exceção? Ora, neste ponto Agamben auxilia a elucidar ao propor que exceção se torna claramente técnica de governo. Esta tecnologia é utilizada para assuntos considerados capitais, a de- 
pender dos contextos, e menos como medida de urgência, assim sempre que a ordem é ameaçada e planos de governo são travados.

Deparamo-nos num livro de Agamben com a figura conceitual que ilumina a discussão: o bando. Termo germânico que designa tanto a exclusão de uma comunidade como o comando e a insígnia do soberano, ela é também compreendida se tomarmos a forma "banido" (2002:36). A noção de bando (e banido) diz respeito ao poder do Estado de deixar sujeitos à mercê, abandonados; assim, por conclusão lógica, refere-se também aos que estão inclusos nesta ordem e que fizeram um "contrato" que domestica e exige obediência. Portanto, novamente Agamben oferece pistas para pensar que nesta interseção entre poder, soberania e governo é crucial o controle do limiar da ordem política. O Estado pode ser benfeitor e inclusivo, mas também pode marcar quem está fora na arbitrariedade do poder - exclusão da política e das políticas.

Como eventual zona de anomia e indistinção entre ordem jurídica e exceção, o banido enquanto excluído não parece estar totalmente fora do ordenamento, mas à mercê. Esta possível vinculação ao "fora" (tanto quanto o "dentro") exerce efeitos expressivos, e quem está dentro aceita o pacto para preservar sua vida em favor de benesses. $\mathrm{O}$ argumento aqui sublinhado consiste em aludir que o conceito de bando é a pistachave para pensar a discutida relação entre violência e Estado e entre a indecisão de desejo e repulsa às ações do Estado via desenvolvimento.

Sobrevoando este tema, Taussig (1992) discorre sobre a ambiguidade entre o sagrado e a fascinação do Estado sobre os sujeitos, combinada com o desgosto, isto é, um misto entre atração sedutora e repulsão (tema abordado também em Taussig, 1997). Particularmente, é frutífera a aproximação disto com a visão weberiana, para quem o Estado aglutina razão e o monopólio legítimo da violência, que aparece recorrentemente em Foucault também. O monopólio é legítimo porque uma determinada razão o estaria amparando. No entanto, Taussig apresenta um argumento inverso, uma espécie de "racionalidade irracional" que pode estar por trás do problema. Se as pessoas enfrentam mensagens contraditórias de medo e esperança, desejo e repulsa em relação ao Estado, Taussig (1992) - também partindo dos escritos de Benjamin - observa que essa violência pode não possuir racionalidade em última instância, mas é uma violência em si e misteriosa.

Mais que governamentalidade generalizada de ponta a ponta da sociedade, uma mensagem possível da noção de bando e da perspectiva da 
ambiguidade atração-repulsa está na sedação que emerge junto à sedução (na feliz expressão de Buck-Morss, 2000). Esses problemas parecem oferecer elementos decisivos no que tange ao tema do desenvolvimento. O Estado pode garantir sua providência se igualmente exigir obediência legal como obrigação, portanto, despolitizando as ações, os conflitos sociais e as insurgências (Ferguson, 1990) no mesmo momento em que politiza a vida ao incluí-la, dispondo-a no âmbito das técnicas de governo e de gestão. Sob esta insígnia os problemas do desenvolvimento podem ser lidos, pois caberia ao Estado incorporar simultaneamente o papel de máquina antipolítica e providencial de governo em que se conjugam biopoder e violência a fim de administrar a vida.

\section{CERTIFICAÇÕES, TECNOLOGIA "INAPROPRIADA" E A RUÍNA COMO METÁFORA DO DESENVOLVIMENTO}

Compreender os processos sociopolíticos que envolvem o Estado, as organizações da sociedade e os indivíduos no Brasil oportuniza testarmos os argumentos antes examinados. Nesta seção, apresentam-se dados de pesquisa focando a interação com práticas sociais, processos de desenvolvimento e governo. O caso examinado, oriundo de investigações prévias do autor, diz respeito aos agricultores e às organizações vinculadas ao Estado que desempenham ações para agricultura ecológica.

Desde meados dos anos 1990 até 2007, o Brasil vinha sendo pressionado para criar regras para os alimentos orgânicos. Esse processo foi implantado primeiramente pelos países do hemisfério Norte e exerceu efeitos no país quando a então Comunidade dos Estados Europeus e os Estados Unidos efetivaram suas normas. O Ministério da Agricultura, Pecuária e Abastecimento do Brasil convidou entidades atuantes com grupos de produtores para estabelecer marcos para a produção ecológica no país e, simultaneamente, discutir os processos de certificação. Esse diálogo entre o Ministério e as entidades durou anos, e a questão central girava em torno de que dificilmente o Brasil escaparia de uma política de normas e de certificação de alimentos orgânicos.

Exatamente no mesmo período, a Organização Mundial do Comércio aprova regras globais para tratamento de propriedade intelectual que precisam ser legalizadas nos países signatários. Se desde o fim do século XIX havia acordos internacionais neste âmbito, somente a partir de 
1994 a regulamentação transnacional torna-se semelhante à força de lei com possibilidades de sanções e penalidades. Parte importante de leis de propriedade intelectual no Brasil é do período de 1996 a 1998, que definirá os modos de apropriação sobre material genético vegetal, assunto capital para agricultores. Se compararmos brevemente estes dois vetores convergentes - propriedade intelectual e certificação (um tipo especial de marca e, portanto, igualmente nos termos de proteção intelectual) -, ocorre a orquestração neoliberal do "desenvolvimento" no plano internacional para o qual as organizações e Estados fornecem condições para a ação de agentes. O caso brasileiro, contudo, parece demonstrar que o Estado tem ainda outras características.

A pesquisa entre os grupos de agricultores ecológicos do oeste de Santa Catarina mostra que, para os indivíduos, o Estado deveria ser um ator primordial na divulgação e na implementação da agroecologia, facilitando processos de conversão de propriedades e ampliando canais de comercialização, aspectos que de fato as entidades estatais realizam. Todavia, parece estar presente para a quase integralidade dos interlocutores em campo que na ordem estatal impera a ação lenta e burocrática; os relatos forneceram a imagem do Estado entendido enquanto sujeito, como se fosse um ente "pesado" que, com dificuldades, está atrasado em relação ao que a sociedade faz. Quando age passa a impressão de ter um aspecto desarticulado. Na mesma medida em que consideram o Estado ineficiente e devagar, agricultores demonstram que a partir dele a agroecologia pode adquirir melhores condições. "Quase não há apoio" era uma expressão recorrentemente escutada, o que significava algo muito distinto de não existirem intervenções.

O caso dos mediadores sociais sugere as tensões sobre o que devem ser as atividades dos quadros estatais para os agricultores. Comparando-se a atuação de indivíduos lotados em instituições estatais aos agricultores-líderes, percebe-se claramente uma inversão de papéis. Pessoas e entidades das quais se esperam conhecimento técnico e facilidades para o acesso a políticas públicas não exercem plenamente estas funções, abrindo possibilidades dos "espaços vazios" em que se inserem a mediação exercida pelas associações da sociedade ou cooperativas de agricultores. No caso da extensão rural, é emblemático que agricultores-líderes se posicionem como conhecedores tanto quanto os experts em agroecologia. De qualquer maneira, o trabalho de mediação dos membros da Rede e dessas vozes dissidentes no interior do corpo 
do Estado precisou "tocar" e ressoar profundamente nos quadros majoritários para que eles se movimentassem.

Estes aspectos direcionam ao tema da ambivalência que aparece quando agricultores avaliam o Estado. O que usualmente estrutura as ações nesse quadro não é uma reação a condições impostas por instâncias externas, mas uma percepção coletiva das possibilidades e dos limites que as transformações - no âmbito jurídico-político - permitem aos grupos. Leis sobre agricultura ecológica, regramentos sobre certificação, controle sobre associações, promoção por meio de políticas públicas para o meio rural - são todas ações que tornam as pessoas, por vezes, com receio de intrusão excessiva e também criam oportunidades a serem aproveitadas.

Como compreender esses processos? Essas características aparecem em diversos aspectos da estrutura organizacional e legal do Estado, mas um típico exemplo pode ser citado: as recentes legislações sobre certificações, o excesso de selos e de normas de produtos orgânicos nos âmbitos nacional e estadual (somadas às leis municipais) sugerem sobreposições e sombreamentos, interpretações confusas e problemas de aplicação. Leis, instruções normativas e decretos foram aprovados com a sustentação em processos participativos e articulações de setores da sociedade ${ }^{6}$, inclusive com mecanismos de ampla divulgação, tal como a cartilha "O Olho do Consumidor", publicada em 2009 com trabalho artístico do cartunista Ziraldo.

Nesse conjunto de procedimentos jurídicos, as certificações participativas, difundidas no Brasil e fruto da organização dos grupos de agricultores/consumidores, foram incluídas como legítimas e eficazes. Entidades da sociedade civil organizada podem gerar e administrar selos de certificação de alimentos orgânicos e esses procedimentos inauguraram os sistemas de regulação de qualidade orgânica (não somente no país) para apenas depois serem englobados pelas normativas legais. No entanto, os mesmos textos normativos tiveram adendos cruciais para demarcar a diferenciação entre as certificações independentes (consagradas como sistema "perito", imparcial e científico) e os sistemas de garantia participativa em que a separação entre verificadores e verificados não é necessária. A hierarquização não ficou evidente no texto, mas existe, e grupos sociais com maior capacidade de articulação e poder obtiveram êxito para que no âmbito do Estado os sistemas 
de garantias sejam - e poder-se-ia afirmar inspirando-se em Agamben - incluídas para serem "excluídas".

A partir das novas normas para os sistemas de certificação orgânica no Brasil, alguns depoimentos demonstram desaprovação e a sensação de imposição. Além de desconstituir textualmente, criaram-se recentemente mais mecanismos de controle externos e adendos que encarecem o orçamento das organizações que administram as garantias. Com a aprovação das normas em âmbito nacional, o controle sobre as organizações não governamentais e entidades aumentou. Particularmente, observa-se nesse cenário a obrigação das Comissões Estaduais da Produção Orgânica (CPOrgs) fiscalizarem a atuação das entidades e igualmente a inscrição no Ministério da Agricultura para legitimar o selo. Adicional a isto, há a obrigatoriedade de que cada entidade responsável por um selo participativo possua comissões e conselhos para observância de recursos financeiros. Eram associações que já partilhavam normas e regras gerais sobre produção ecológica, cada qual com modos de regulação socialmente aceitos nos locais de atuação. Como meio de dar apoio e legitimidade ao processo participativo o Estado acaba por verticalizar o controle e dispor de regras de administração no âmbito de associações e redes de garantia. A contradição do processo está no fato de que as entidades foram pioneiras e participam da história da construção da agricultura ecológica no Brasil. Depois que passaram a ser visibilizadas, apoiadas e promovidas, começam a enfrentar legislações padronizadoras, caminhos burocráticos que dão lentidão aos processos e necessidade de novos modelos de organização, que tornam a certificação mais cara e demandam mais tempo de trabalho (por exemplo, incessantes procedimentos de recadastramento de produtores junto às entidades).

No entanto, creio não ser possível uma leitura das ações estatais (nos diferentes níveis de governo) somente como imposição de regras e violência simbólica. De certo modo, emerge certa aceitação desse controle, fato verbalizado entre os produtores pela ideia de construção de um sistema mais aprimorado para os alimentos orgânicos, sua divulgação e consolidação ${ }^{7}$. Particularmente, as pessoas envolvidas observam que existe um efeito de poder e harmonização que está relacionado a regulamentações de escopo nacional e internacional. Contudo, costumam destacar os resultados benéficos de tais intervenções para a legitimação da agricultura ecológica e o reconhecimento da certificação participativa em outros espaços da sociedade. 
Durante determinado momento ao longo da realização desta pesquisa com agricultores do oeste catarinense, o Estado passou a promover bancos de sementes para livre acesso - e neste feixe de problemas emaranham-se as categorias de propriedade intelectual e controle sobre material genético. Através da entidade de pesquisa agropecuária e extensão rural de Santa Catarina, abriram-se espaços para pesquisa e manutenção de variedades. O banco de sementes não é a única ação, mas significativo no que diz respeito ao controle ou não do Estado sobre material genético, fato que importa aos produtores rurais. Enquanto percebem a importância da entidade em realizar este projeto, os agricultores manifestam preferência em manter certo controle sobre as sementes (que entre eles redunda no controle sobre os conhecimentos associados aos seus usos). Nos distintos momentos em que acompanhei os grupos, observei que esse fato não tem intenção de tornar as sementes uma propriedade e limitar o acesso de outros, porém existe o receio de que o Estado possa ser ineficiente ou, num momento qualquer, limitar seu acesso aos recursos vegetais.

É conhecida a história de que as sementes paulatinamente deixaram de ser trocadas no mundo rural para se tornarem mercadorias "melhoradas" e vendidas por empresas de biotecnologia. Recentemente, isto configuraria uma fase distinta que Shiva e Jalees (2006) afirmam pertencer à "revolução do gene", não mais à "revolução verde", propulsora da modernização do campo. Enquanto a última era administrada por pesquisa e recursos públicos, a primeira sustenta-se em capital privado, empresas, produção de transgênicos e controle de direitos intelectuais. A produção de sementes híbridas ensejou um processo de homogeneização dos cultivares e teve efeitos diretos na utilização e no modo de apropriação por parte dos agricultores ao redor do mundo.

O problema das sementes, por sua natureza central na agricultura, vem a ser crucial em outro aspecto, já que denuncia a desarticulação e a violência que esferas do Estado efetuam. A partir de entrevistas realizadas, observou-se que os sistemas de crédito rural possuem catálogos de sementes recomendadas para o plantio, particularmente de grãos. Esse sistema funciona como base para concessão de crédito rural e, quando a semente é "local" (rústica, também chamada de crioula), os consultores tendem a reprovar o crédito ao agricultor por estas sementes serem consideradas tecnologia inapropriada - expressão de significativo impacto. É inevitável interpretar isto como um poder de veto em que se aglutinam o poder do Estado com empresas públicas ou priva- 
das de biotecnologia, uma vez que unicamente sementes protegidas por patentes ou "melhoradas" são as recomendadas; estas têm caráter híbrido ou são resultado de modificação genética. Supostamente possuem resiliência, isto é, têm maior aptidão a intempéries e pragas.

Observe-se que o sistema de crédito, parcialmente público, é parte do mesmo Estado que cria programas para sementes rústicas e crioulas. Brumer e Spanevello (2012) mostram que o caso do crédito rural para mulheres encontra paralelos: a demanda particular do programa com "recorte" de gênero não foi bem internalizado nos bancos e muitas vezes não tem interesse em empréstimos diminutos, em que pese a relevância para as mulheres beneficiárias. Contudo, tal qual o problema da referência à "tecnologia inapropriada", o crédito rural no Brasil passa pela mediação dos agentes financeiros, que são seletivos na escolha do financiamento, inclusive sobre quem será o tomador de empréstimo, e possuem poder de recomendar apoio a atividades que sejam de fato produtivas e impliquem consumo de insumos agrícolas, o que nem sempre está no horizonte do público interessado em tomar o recurso financeiro (idem).

É necessário perceber que, pelo menos no que diz respeito às sementes e sua seletividade, as normativas convertem-se em constrangimento e incidem sobre a vida com grande impacto, tornando-se válido anular a multiplicidade de variedades vivas em prol da hegemoneidade e da estabilidade. O problema é que estaríamos num espaço em que a anulação da multiplicidade das variedades vegetais se justifica com a suposta supressão de riscos. Organismos vivos (sementes) ancestrais fundamentados em conhecimentos mantidos por grupos camponeses ao longo de gerações e cruzando continentes são desconstituídos por pessoas, programas e sistemas profissionais que trabalham para a promoção do desenvolvimento. Não exatamente uma biopolítica, tal como Foucault examinou sobre a vida humana, mas uma política com efeitos na vida biológica e na alimentação, o que está no limiar de produzir vida artificialmente e aniquilar a sua espontaneidade.

Na introdução de seu Dicionário do Desenvolvimento, Sachs escreve: "A ideia de desenvolvimento permanece como uma ruína na paisagem intelectual e já chegou o tempo de escrevermos seu obituário" (1992:4-5, tradução livre). A metáfora da ruína quando está em questão o que se passa com agricultores ecológicos não encontra melhores ecos do que o sociodrama da erosão. A erosão da biodiversidade tem consequências 
diretas nos conhecimentos a ela articulados, perdendo-se a forma de vida vegetal dissolve-se também o saber a ela associado e caminha-se, num passo, à homogeneização da agricultura e à padronização do social assim administrado. Portanto, o problema vincula a diminuição da diversidade da vida vegetal ao afunilamento dos conhecimentos sobre o mundo. Argumentos variados e depoimentos de interlocutores de pesquisa sugerem que este processo tem o ápice na programação genética da morte pela biotecnologia. No ímpeto para conseguir controlar as variedades de sementes e fazer delas mercadorias lucrativas, a proteção patentária foi o instrumento que possibilitou o investimento das empresas no ramo, de tal modo que, no limite extremo, a vida foi programada para não gerar mais vida (variedades que não geram sementes para evitar a apropriação "indevida" por produtores rurais e replantio nas safras seguintes). A erosão expressa em sua imagem o que o modelo de desenvolvimento agrícola posto em movimento desencadeou. Na indecisão entre vida e morte:

Se, em todo Estado moderno, existe uma linha que assinala o ponto em que a decisão sobre a vida torna-se decisão sobre a morte, e a biopolítica pode converter-se em tanatopolítica, tal linha não mais se apresenta hoje como um confim fixo [...]. [É] uma linha em movimento que se desloca para zonas sempre mais amplas da vida social, nas quais o soberano entra em simbiose cada vez mais íntima não só com o jurista, mas também o médico, com o cientista, com o perito, com o sacerdote. (Agamben, 2002:119)

Num panorama em que a ciência e os poderes burocráticos se mesclam, a força da lei associa-se ao saber científico perito efetuando uma despolitização que tem relação direta com as iniciativas em torno do desenvolvimento. Por outro lado, a indecidibilidade soberana sugere encontrar paralelos com a indecisão ou ambivalência dos atores em "jogar" com a máquina estatal e suas formas de administrar. A força mística da lei e o receio do banimento oferecem saídas curiosas, tais como estar no limite de sedução e da sedação pela máquina providencial. Esta capacidade de agência e os jogos de poder relacionados podem indagar a eficácia do poder soberano em Agamben, ponto ao qual retornarei nas considerações finais. Ainda assim, a chance de banimento pode estar no horizonte, por isto mesmo tais jogos são relações cuidadosas para os atores da sociedade civil. De alguma maneira, ser excluído das políticas parece ser ameaça mais real do que da política, pois a voz, a palavra no espaço público e a participação aparecem pou- 
co, ao passo que a gerência e a normalização se fazem presentes nas formas de governo.

\section{CONSIDERAÇÕES FINAIS}

O plano de análise empírica proposto neste artigo manifesta potencialidades de interpretação pela linha de argumentação FoucaultAgamben com uma tensão originada em textos seminais de Benjamin, particularmente acerca de direito, lei e violência. Os exemplos mobilizados apresentam situações em que grupos assumem posições sociais em coordenadas imersas em relações desiguais. Para tal a narrativa está em afirmar que as condições de mercado são apenas asseguradas pelo Estado para a boa competição; antes, em Foucault esse espaço é produzido como lugar do não governo, gerenciado para se constituir desse modo, e nisto potencializa-se a concorrência econômica simultaneamente à autorresponsabilidade de cada participante. O Estado pode se afastar do planejamento do desenvolvimento como no passado recente para que a veridição do mercado exponha um mundo social de livre atuação, porém administra a vida produzindo um tipo de sociedade e de economia através de atos excepcionais, normalização, gerência do social e governo do desenvolvimento.

Refletindo criticamente acerca dos referenciais apresentados ao longo do artigo, um problema pendente está em discutir a relevância que a noção de governamentalidade - e todo o aparato conceitual que gravita em torno desta - possui ao se pensarem processos históricos fora do eixo euro-americano. Cesarino (2012), em estudo sobre cooperação entre o Brasil e países africanos, ressalta que recentes pesquisas sobre desenvolvimento e colonialidade apontam que referenciais distintos podem apreender melhor tais processos, tal como a noção gramsciana de hegemonia, entre outras. Seguramente, os estudos que partem dos referenciais propriamente latino-americanos propõem modalidades endógenas como as principais e se afastam do pós-estruturalismo (Mignolo, 2000) ou se aproximam de problemas de uma modernidade periférica nos trópicos (Domingues, 2009).

Esses dilemas também se apresentam à dimensão da agência enquanto conceito central da sociologia contemporânea. Parfitt (2009) critica a noção de vida nua recuperado por Agamben propondo que qualquer vida é culturalmente rica e a mera vida biológica humana não se encontra em lugar algum. Este é um argumento válido de se destacar, pois 
Agamben parece afastar-se dos processos reais e contextuais em que soberania, exceção e violência são culturalmente negociados e, assim, adquirem expressão particular em cada caso - sendo que os recentes protestos nas capitais brasileiras bem sinalizam a urgência de uma thick description da opacidade da soberania e das diferentes camadas de poder-resistência. Entretanto, Agamben não simplifica a análise, mostrando que "não existem, primeiro, a vida como dado biológico natural e a anomia como estado de natureza e, depois, sua implicação no direito por meio do estado de exceção" (Agamben, 2004:132). Inversamente, $\mathrm{o}$ autor segue afirmando na mesma página que a "[...] possibilidade de distinguir entre vida e direito, anomia e nomos coincide com sua articulação na máquina biopolítica. A vida pura e simples é um produto da máquina e não algo que preexiste a ela $[\ldots .$.$] ".$

Variações de biopolítica emergem dando contornos de que essa noção é válida como um recurso de resistência e criação, tal como aparece em Roberto Esposito, e a oportunidade de uma biopolítica afirmativa (2008). Situação interpretativa instigante, pois quiçá remete a uma mutação no pensamento de Foucault em seus últimos cursos. Saber se a biopolítica é o conjunto de biopoderes ou lugar de emergência de contrapoderes, nas palavras de Boyer (2012), é o panorama legado pelo autor francês e o debate está em revelar se esta versão da biopolítica pode ser associada à produção de subjetividades não totalmente subjugadas.

Deste modo, a indagação presente é se o desenvolvimento revigorado representa uma ordenação que articula despolitização e providência, administração normalizadora e vida nua no ditame do poder/violência, na figura do Estado desejado e temido. Cabe registrar que para Agamben liberar a vida do cruzamento entre a norma e a lei pode se traduzir na crítica radical da coincidência entre a lei e a vida. Nesta história, seria possível experimentar o "desejo de liberar a vida da culpa assegurada pelo contrato legal com o Estado [...]" e, ainda que esta passagem seja recuperada de um contexto argumentativo distinto, seu prosseguimento vale o risco da transposição e, para tal, “[...] este seria um desejo que dá condições a uma violência contra a violência, aquela que procura liberar a vida do contrato de morte com a lei" (Butler, 2006:211; tradução livre).

(Recebido para publicação em julho de 2013) (Aprovado para publicação em abril de 2014) 


\section{Guilherme F. W. Radomsky}

\section{NOTAS}

1. Para esta análise, privilegiam-se os cursos após Vigiar e Punir e em que Foucault ainda não passara para o tema da ética e da subjetividade. Portanto, é o período compreendido entre 1975 e 1979 com os cursos Em Defesa da Sociedade, Segurança, Território e População e O Nascimento da Biopolítica. O problema metodológico da descontinuidade na investigação histórica será eventualmente comentado, tal como descrito na Arqueologia do Saber.

2. Tema controverso, alguns leitores tendem a não considerar a importância que Foucault atribui ao Estado. Ao examinar-se Segurança, Território, População isto parece não se sustentar, o que ocorre também em O Nascimento da Biopolítica (além de outros momentos da obra do autor). Senellart (2008:520) discorre sobre as investigações de Foucault sobre o Estado e afirma: "A gestão dos 'processos biossociológicos das massas humanas', ao contrário das disciplinas aplicadas no âmbito de instituições limitadas (escola, hospital, quartel, fábrica etc.), envolve de fato o aparelho de Estado". É no nível do Estado que se encontram os "órgãos complexos de coordenação e de centralização" necessários a esse fim. A biopolítica só pode ser concebida, portanto, como "uma biorregulação pelo Estado".

3. Suárez-Krabbe (2012) afirma que é exígua a compreensão de Foucault sobre a subjetividade moderna, como se ela não fosse, de algum modo, constitutiva e constituída na perversa relação com os sujeitos colonizados (a subjetividade colonial). O conhecido ensaio de Spivak (2010) também demonstra como os novos mecanismos de poder na Europa dos séculos XVII e XVIII tinham relação com a exploração da terra e da natureza em outros lugares, sem que Foucault mencione isto com clareza, portanto, sob o registro soberano de poder.

4. Em Homo Sacer, Agamben (2002:96) traça a história da relação entre vida e morte, já analisada por Foucault. Vitae necisque potestas figuraria no direito romano e partiria da relação entre pai e filho e o poder de morte do primeiro sobre o segundo. Ao longo da história, o pai torna-se pai do povo e da pátria, e o poder de morte é estendido ao povo. Assim, a vida se politiza por sua matabilidade.

5. Como não será possível mostrar todas as articulações entre a teologia política e econômica e as genealogias de uma teoria do poder e do governo modernos, com momento crucial no cristianismo, remete-se o leitor para Agamben (2011) e a leitura de Sordi (2013).

6. As mais importantes são a Lei $\mathrm{n}-10.831$, de 23 de dezembro 2003 que dispõe sobre a agricultura orgânica, o Decreto $\mathrm{n}$-6.323, de 27 de dezembro de 2007 que regulamenta a lei anterior e a Instrução Normativa no 64 , de 18 de dezembro de 2008 do Ministério da Agricultura, Pecuária e Abastecimento.

7. Com a aprovação das normas de orgânicos e dos sistemas participativos de garantia, o Ministério do Desenvolvimento Social e o Ministério do Desenvolvimento Agrário em conjunto passaram não somente a aceitar certificações participativas nas suas compras (pelo Programa de Aquisição de Alimentos - PAA) como exigir o selo para conceder aos agricultores ecológicos preço prêmio de $30 \%$ superior aos pagos aos convencionais. A noção de que é cabível premiar as "condutas sustentáveis" é notável. 


\section{Biopolítica e Desenvolvimento?}

\section{REFERÊNCIAS BIBLIOGRÁFICAS}

AGAMBEN, Giorgio. (2002), Homo Sacer: O Poder Soberano e a Vida Nua I. Belo Horizonte, Editora UFMG.

(2004), Estado de Exceção. São Paulo, Boitempo.

(2011), O Reino e a Glória: Uma Genealogia Teológica da Economia e do Governo. São Paulo, Boitempo.

BENJAMIN, Walter. (1986), "Crítica da Violência. Crítica do Poder", in Documentos de Cultura, Documentos de Barbárie: Escritos Escolhidos. São Paulo, Cultrix, Edusp, pp. 160-175. (Seleção e apresentação Willi Bolle).

BOYER, Amalia. (2012), "Biopolítica y Filosofía Feminista". Revista de Estudios Sociales, no 43 , pp. 131-138.

BRIGG, Morgan. (2002), "Post-development, Foucault and the Colonisation Metaphor". Third World Quarterly, vol. 23, no 3, pp. 421-436.

BRUMER, Anita e SPANEVELLO, Rosani. (2012), “O Papel dos Mediadores no Acesso das Mulheres ao PRONAF Mulher". Revista Anthropológicas, vol. 23, pp. 93-117.

BUCK-MORSS, Susan. (2000), Dreamworld and Catastrophe: The Passing of Mass Utopia in East and West. Cambridge, MIT Press.

BUTLER, Judith. (2006), “Critique, Coercion, and Sacred Life in Benjamin's Critique of Violence", in H. De Vries e L. Sullivan (eds.), Political Theologies: Public Religions in a Post-secular World. New York, Fordham University Press, pp. 201-219.

CESARINO, Letícia. (2012), "Anthropology of Development and Challenge of SouthSouth Cooperation". Vibrant, vol. 9, no 1, pp. 509-537.

CORBRIDGE, Stuart. (2007), “The (Im)possibility of Development Studies”. Economy and Society, vol. 36, no 2, pp. 179-211.

CRUSH, Jonathan (ed.). (1995), Power of Development. London, Routledge.

DE VRIES, Pieter. (2007), “Don't Compromise your Desire for Development! A Lacanian/Deleuzian Rethinking of the Anti-politics Machine". Third World Quarterly, vol. 28, no 1, pp. 25-43.

DINIZ, Eli. (2011), “O Contexto Internacional e a Retomada do Debate sobre Desenvolvimento no Brasil Contemporâneo (2000/2010)". DADOS - Revista de Ciências Sociais, vol. 54, no 4 , pp. 493-531.

DOMINGUES, José Maurício. (2009), A América Latina e a Modernidade Contemporânea: Uma Interpretação Sociológica. Belo Horizonte, UFMG Editora.

ESCOBAR, Arturo. (1984), “Discourse and Power in Development: Michel Foucault and the Relevance of his Work to the Third World". Alternatives, vol. 10, pp. 377-400.

(1995), Encountering Development: The Making and Unmaking of the Third World. Princeton, Princeton University Press.

ESPOSITO, Roberto. (2008), Bíos: Biopolitics and Philosophy. Minneapolis, University of Minnesota Press. 


\section{Guilherme F. W. Radomsky}

ESTEVA, Gustavo. (1992), "Development”, in W. Sachs (ed.), The Development Dictionary: A Guide to Knowledge as Power. London, Zed Books, pp. 6-25.

FERGUSON, James. (1990), The Anti-politics Machine: "Development", Depoliticization, and Bureaucratic Power in Lesotho. Cambridge/New York, Cambridge University Press.

FLEURY, Lorena Candido. (2013), Conflito Ambiental e Cosmopolítica na Amazônia Brasileira: Construção da Usina Hidrelétrica de Belo Monte em Perspectiva. Tese (Doutorado em Sociologia), Universidade Federal do Rio Grande do Sul, Porto Alegre.

FOUCAULT, Michel. (1999), Em Defesa da Sociedade. Curso no Collège de France (1975-1976). São Paulo, Martins Fontes.

. (2002), As Palavras e as Coisas: Uma Arqueologia das Ciências Humanas. São Paulo, Martins Fontes.

. (2008a), Segurança, Território, População: Curso no Collège de France (1977-1978). São Paulo, Martins Fontes.

. (2008b), O Nascimento da Biopolítica. Curso no Collège de France (1978-1979). São Paulo, Martins Fontes.

HOBART, Mark (ed.). (1993), An Anthropological Critique of Development: The Growth of Ignorance. London, Routledge.

KERSTENETZKY, Celia. (2011), “Welfare State e Desenvolvimento". DADOS - Revista de Ciências Sociais, vol. 54, no 1, pp.129-156.

LATOUCHE, Serge. (2009), Pequeno Tratado do Decrescimento Sereno. São Paulo, Martins Fontes.

MIGNOLO, Walter. (1995), The Darker Side of the Renaissance: Literacy, Territoriality, and Colonization. Ann Arbor, University of Michigan Press.

. (2000), Local Histories/Global Designs: Coloniality, Subaltern Knowledges, and Border Thinking. Princeton, Princeton University Press.

PARFITT, Trevor. (2009), "Are the Third World Poor Homines Sacri? Biopolitics, Sovereignty, and Development". Alternatives, vol. 34, no 1, pp. 41-58.

POVINELLI, Elisabeth. (2012), "The Will to Be Otherwise/The Effort of Endurance". The South Atlantic Quarterly, vol. 111, no 3, pp. 453-475.

QUIJANO, Aníbal. (2000), "Coloniality of Power, Eurocentrism, and Latin America". Nepantla: Views from the South, vol. 1, no 3, pp. 533-580.

RABINOW, Paul e DREYFUSS, Hubert. (1982), Michel Foucault, beyond Structuralism and Hermeneutics. Chicago, University of Chicago Press.

RIBEIRO, Gustavo Lins. (2008), "Poder, Redes e Ideologia no Campo do Desenvolvimento". Novos Estudos Cebrap, no 80, pp. 109-125.

RIST, Gilbert. (2008), The History of Development: From Western Origins to Global Faith. (3a ed.). London, Zed books.

RUIZ, Castor Bartolomé. (2012), "A Sacralidade da Vida na Exceção Soberana, a Testemunha e sua Linguagem. Releituras Biopolíticas da Obra de Giorgio Agamben". Cadernos IHU, vol. 10, no 39, pp. 1-50. 
SACHS, Wolfgang. (1992), "Introduction", in W. Sachs (ed.), The Development Dictionary: A Guide to Knowledge as Power. London, Zed Books, pp. 1-5.

SENELLART, Michel. (2008), "Situação dos Cursos", in M. Foucault, Segurança, Território, População: Curso no Collège de France (1977-1978). São Paulo, Martins Fontes, pp. 495-538.

SHIVA, Vandana e JALEES, Kunwar. (2006), Seeds of Suicide: The Ecological and Human Costs of Seed Monopolies and Globalisation of Agriculture. New Delhi, Navdanya.

SORDI, Caetano. (2013), "Da Secularização à Profanação, da Escatologia ao Messianismo: Giorgio Agamben e as Assinaturas Teológicas do Poder Moderno". Debates do NER, ano 14, no 24, pp. 141-164.

SPIVAK, Gayatri C. (2010), Pode o Subalterno Falar? Belo Horizonte, UFMG Editora.

STOREY, Andy. (2000), "Post-development Theory: Romanticism and Pontius Pilate Politics". Development, vol. 43, no 4, pp. 40-46.

SUÁREZ-KRABBE, Julia. (2012), “Pasar por Quijano, Salvar a Foucault. Protección de Identidades Blancas y Decolonización". Tabula Rasa, no 16, pp. 39-57.

SYLVESTER, Christine. (2006), "Bare Life as a Development/Postcolonial Problematic". The Geographical Journal, vol. 172, no 1, pp. 66-77.

TAUSSIG, Michael. (1992), The Nervous System. New York, Routledge.

(1997), The Magic of State. New York, Routledge.

WERNECK VIANNA, Luiz. (2012), “A Modernização Brasileira e a Política Burguesa Cinzenta (entrevista especial)". Revista IHU, ano 12, vol. 392.

ZIAI, Aram. (2007), “The Ambivalence of Post-development: Between Reactionary Populism and Radical Democracy", in A. Ziai (ed.), Exploring Post-development: Theory and Practice, Problems and Perspectives. London, Routledge, pp. 111-128. 


\section{RESUMO}

Biopolitica e Desenvolvimento? Foucault e Agamben sobre Estado, Governo e Violência

Este artigo analisa as relações entre biopolítica e desenvolvimento sob o ângulo das noções de Estado, governo e violência. O objetivo consiste em examinar elementos analíticos que gravitam em torno de perspectivas críticas do desenvolvimento buscando um eixo interpretativo sobre a ambivalência das ações do Estado a partir de duas possibilidades teóricas que convergem no pensamento de Giorgio Agamben: a análise do biopoder e do governo em Foucault e as articulações entre violência e lei que remetem a Walter Benjamin. A reflexão sobre os argumentos teóricos é realizada examinando-se dados oriundos de pesquisa de abordagem qualitativa sobre políticas para a agricultura ecológica no sul do Brasil. As conclusões mostram que o desenvolvimento e seus benefícios podem ser problematizados pelo olhar do biopoder e da violência, que reconfiguram o que seja desenvolvimento, menos como expansão do bem-estar e mais como impulso modernizante de mudança que se ampara em administrar a vida.

Palavras-chave: desenvolvimento; violência; biopolítica; biopoder; Estado

\section{ABSTRACT \\ Biopolitics and Development? Foucault and Agamben on the State, Government and Violence}

This article analyzes the relationship between biopolitics and development from the perspective of the notions of the State, government and violence. The goal consists of examining the analytical elements which gravitate around critical perspectives of development seeking an interpretive axis for the ambivalence of the actions of the State based on two theoretical possibilities which converge in the thought of Giorgio Agamben: the analysis of biopower and government in Foucault and the articulations between violence that allude to Walter Benjamin. The reflection on the theoretical arguments is carried out examining data from the qualitative survey on agro-ecological policies in southern Brazil. The conclusions show that development and its benefits can be problematized from the prism of power and violence, reconfiguring development more as a modernizing impulse that hopes to manage life than the expansion of well-being.

Keywords: development; violence; biopolitics; biopower; State 


\section{RÉSUMÉ}

\section{Biopolitique et Développement? L'État, le Gouvernement et la Violence chez Foucault et Agamben}

Cet article analyse les relations entre biopolitique et développement sous la perspective des notions d'État, de gouvernement et de violence. Il s'agit à cet effet d'examiner des éléments analytiques gravitant autour des perspectives critiques du développement et de construire un axe interprétatif relatif à l'ambivalence des actions de l'État à partir de deux possibilités théoriques qui convergent dans la pensée de Giorgio Agamben: l'analyse du biopouvoir et du gouvernement chez Foucault et les articulations entre violence et loi qui renvoient à l'œuvre de Walter Benjamin. La réflexion sur les arguments théoriques s'appuiera sur l'examen de données issues d'une recherche qualitative sur les politiques en faveur de l'agriculture biologique dans le sud du Brésil. Les conclusions nous montrent que le développement et ses bénéfices peuvent être mis en perspective sous l'angle du biopouvoir et de la violence, qui reconfigurent ce que serait le développement moins comme une expansion du bien-être que comme un élan modernisateur et transformateur fondé sur l'administration de la vie.

Mots-clés: développement; violence; biopolitique; biopouvoir; État

\section{RESUMEN}

Biopolitica y Desarrollo? Foucault y Agamben sobre Estado, Gobierno y Violencia

Este artículo analiza las relaciones entre biopolítica y desarrollo bajo el prisma de las nociones de Estado, gobierno y violencia. El objetivo consiste en examinar elementos analíticos que gravitan alrededor de perspectivas críticas del desarrollo buscando un eje interpretativo sobre la ambivalencia de las acciones del Estado a partir de dos posibilidades teóricas que convergen en el pensamiento de Giorgio Agamben: el análisis del biopoder y del gobierno en Foucault y las articulaciones entre violencia y ley que remiten a Walter Benjamin. La reflexión sobre los argumentos teóricos se realiza acompañada de datos provenientes de una investigación de abordaje cualitativa sobre políticas para la agricultura ecológica en el sur de Brasil. Las conclusiones muestran que el desarrollo y sus beneficios pueden ser cuestionados mediante la mirada del biopoder y de la violencia, que reconfiguran la definición del desarrollo, menos como expansión del bienestar y más como impulso modernizante de cambio que se ampara en administrar la vida.

Palabras clave: desarrollo; violencia; biopolítica; biopoder; Estado 